\title{
Fluid properties and their seismic responses: Implications for Direct Hydrocarbon Indicators
}

David Curia ${ }^{1}$, Eduardo Trinchero² and Luis Vernengo ${ }^{2}$

${ }^{1}$ Wintershall Energía S. A., Argentina
${ }^{2}$ Pan American Energy LLC, Argentina
Copyright 2019, SBGf - Sociedade Brasileira de Geofísica

This paper was prepared for presentation during the $16^{\text {th }}$ International Congress of the Brazilian Geophysical Society held in Rio de Janeiro, Brazil, 19-22 August 2019.

Contents of this paper were reviewed by the Technical Committee of the $16^{\text {th }}$ International Congress of the Brazilian Geophysical Society and do not necessarily represent any position of the SBGf, its officers or members. Electronic reproduction or storage of any part of this paper for commercial purposes without the written consent of the Brazilian Geophysical Society is prohibited.

\section{Abstract}

The recent trends in seismic exploration for detailed investigation of the effect of fluid and rock properties and their influence on seismic amplitudes are the motivation for the present work. In this way, particular interest has the observation that attempts at measuring fluid density and bulk modulus, which is usually carried out at surface temperature and pressure conditions, whereas the seismic response perceives the effect of these parameters at in situ subsurface conditions.

In line with these observations, it was discussing the Batzle and Wang model which helps compute the reservoir parameters of interest at desired temperatures and pressures are discussed. Thereafter, it is included the effect of saturation of the pore fluids using the analysis of Gassmann. Finally, it is used the Zoeppritz equation and its approximations to generate and study the seismic response for a selection of parameters.

The results of the mentioned Batzle and Wang model are compared with laboratory measurements in order to evaluate its capability as a prediction tool for fluid properties. Also the application of this workflow for a case study and the discussion of their results are illustrated.

\section{Introduction}

The three main constituents of a rock are the matrix, the pore space and the pore fluid. The effects due to changes in the properties of these elements are interrelated, and have an influence on the resultant seismic response from the rock formation. As the geology of an area controls the rock and fluid properties, varied depositional scenarios could have an effect on their seismic responses (Chopra and Castagna, 2014). Thus, it is necessary to understand the behavior of the Pvelocity $\left(V_{\mathrm{P}}\right)$, S-velocity $\left(V_{\mathrm{S}}\right)$, and the density in order to recognize the changes in fluid and/or properties as well as predict the effect of those changes on seismic amplitudes.

The seismic response is influenced by the impedance contrast of the fluid and the rock matrix. It exhibits variations of amplitude as a function of offset (AVO), which often can be used as direct hydrocarbon indicators (DHI). Impedance contrasts between fluids at the contacts such as gas-water, or gas-oil could provide Direct Hydrocarbons Indicators (DHI) responses (Chopra and Castagna, 2014). One way to study the seismic response for a given set of rock or reservoir properties is by modeling. Figure 1 shows a flow chart that lists the workflow calculations and the corresponding source from where the data is retrieved or computed.

The basic input elastic parameters (bulk modulus, velocity and density) for modeling can be determined using measurements on rock samples. It is to be noted that any laboratory measurements of, for example fluid density and bulk modulus, are carried out at surface temperature and pressure conditions. But to model the seismic response accurately, these properties should be known at reservoir conditions. The effect of saturation of the pore fluid could be considered using Gassmann (1951) substitution.

The reason for performing the calculations of Figure 1 is the fact that modeling seismic response for a simple gas model may often be found to be inadequate to explain the observed phenomena, as a mixed model with live oil could give a similar response. As direct hydrocarbon indication, AVO anomalies are often seen on seismic data due to a drop in the effective fluid modulus (and thus lower $V_{P}$ ) and density, with $V_{S}$ remaining relatively unchanged. But a reduced fluid modulus alone may not be a gas or no-gas indicator.

Besides, hydrocarbon properties could span a complete range from brine-like to gas-like. In certain situations, the hydrocarbons may be beyond the pseudocritical point, where there is no distinction between the liquid and gas phase. The above conditions could yield a different seismic response.

\section{Models, analysis and predictions}

\section{Batzle and Wang fluid property model}

Batzle and Wang (1992) combined thermodynamic relationships and empirical trends from published data to predict the effect of pressure, temperature and composition on the seismic properties of fluids. Also the fluid properties predicted (see Figure 1b), include the density and bulk modulus, (Bulloch, 1999). The calculations require some basic input variables, which may be determined from the PVT (pressure-volumetemperature) measurements. This can be done on a representative fluid sample or estimated from analogous information, if available, in a nearby well.

The adiabatic compressibility of a fluid is related to its isothermal compressibility through the ratio $\left(\gamma_{0}\right)$ between heat capacities at constant pressure and heat capacity at constant volume, 


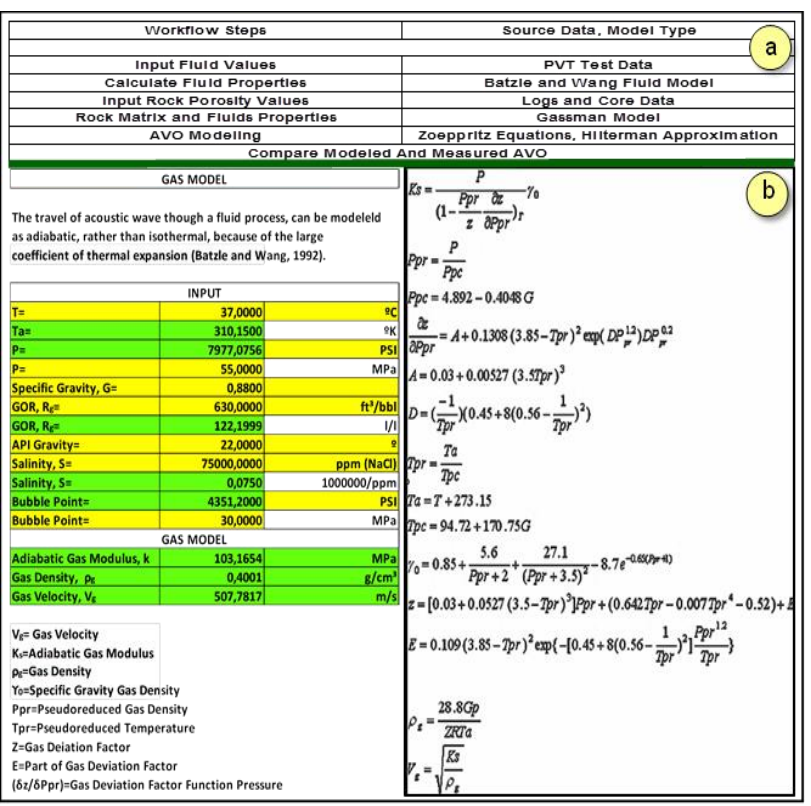

Figure 1. (a) Generalized flow cart for computing seismic response for a reservoir. (b) Spreadsheet for application of Batzle and Wang (1992) model for a gas case at common deep water conditions, where pressure is 55 Mpa and temperature $75^{\circ} \mathrm{C}$. The input data (yellow rows) was collected from well data (PVT) or from other similar reservoirs nearby commonly referred to as analogous.

$\frac{K_{T}}{K_{S}}=\frac{\left(\frac{\partial V}{\partial P}\right)_{T}}{\left(\frac{\partial V}{\partial P}\right)_{S}}=\gamma_{o}($ Young and Freedman, 2012)

Another factor that should be use in the calculations (shown in Figure 1) is the API gravity of the oil, which can have a bearing on their viscosity and composition. Thus, the density and velocity of oil would depend on pressure, temperature and API. In Figure 1b), it is possible to appreciate the Batzle and Wang sample calculations, where the normal pore pressure in the subsurface (in $\mathrm{MPa}$ ) is taken as approximately ten times the vertical depth in $\mathrm{km}$, so that a maximum pore pressure of $50 \mathrm{MPa}$ is considered at approximately $5 \mathrm{~km}$ TVD. The temperature is taken as $75^{\circ} \mathrm{C}$ and specific gravity of gas as 0.88 .

\section{Gassmann-Biot relationships}

Gassmann's equations (Gassmann, 1951) relate the bulk modulus of the rock saturated with fluid $\left(K_{\text {sat }}\right)$, to the bulk modulus of the pore fluid $\left(K_{f}\right)$, the nonporous solid material making up the rock $\left(K_{0}\right)$, and the porous rock frame $\left(K^{*}\right)$ :

$$
\frac{K_{\text {sat }}}{K_{0}-K_{\text {sat }}}=\frac{K^{*}}{K_{0}-K^{*}}+\frac{K_{f}}{\Phi\left(K_{0}-K_{f}\right)}
$$

$$
K_{\text {sat }}=K^{*}+\frac{1-\left(\frac{K^{*}}{K_{0}}\right)^{2}}{\frac{\Phi}{K_{f}}+\frac{(1-\Phi)}{K_{0}}-\frac{K^{*}}{{K_{0}}^{2}}}
$$

Where $\Phi$ = Porosity. These equations are a simplification of the Biot's elastic modeling of porous media (Biot, 1956) valid for low frequencies. They assume a homogeneous mineral modulus and isotropic pore space. The solid material grain bulk modulus and density are determined from the mineralogy of the reservoir matrix. The water/brine and hydrocarbon bulk modulus and density values are computed at reservoir temperature and pressure conditions in the spreadsheet are related to the Batzle and Wang (1992) described above and shown in Figure 2. The $P$ and $S$ wave velocities and bulk density $\left(\mathrm{V}_{\mathrm{pi}}, \mathrm{V}_{\mathrm{si}}\right.$ and $\left.\rho_{\mathrm{bi}}\right)$ values are obtained from well logs and used to calculate the saturated bulk modulus ( $\mathrm{K}_{\mathrm{bs}}$ ) and the dry frame shear modulus $(\mathrm{G})$. Gassmann's relations are used to calculate the dry frame bulk modulus ( $K_{d f}$ ) by applying the saturated bulk modulus (Kbs), determined from well log or laboratory tests. The bulk density $\left(\rho_{b}\right)$ is calculated using a volume weighted average density for the reservoir.

The fluid bulk modulus $\left(\mathrm{K}_{\mathrm{f}}\right)$ is computed using the Reuss (iso-stress) average and it is calculated using the water and hydrocarbon saturations. The saturated bulk modulus $\left(\mathrm{K}_{\mathrm{b}}\right)$ is computed at any desired saturation conditions using the dry frame bulk modulus, solid material bulk modulus, fluid modulus and the porosity. The compressional and shear velocities $\left(V_{p}, V_{s}\right)$ are calculated using the elastic Lamé equations. From the Batzle and Wang model it is presupposed that when gas is at high in situ pressure and temperature conditions (i.e. deep subsurface conditions), it has physical properties similar to those of light oil.

\section{Pressure and temperature analysis}

For doing this it was used the Batzle and Wang (1992) model. The job is done on saturation, pressure, hydrocarbon type (i.e. variable API or GOR), which are expect to change for different reservoir scenarios under different temperature and pressure conditions. Thereafter, it was used Gassmann's equations for calculating the variation of such elastic properties (e.g. Al) with changing fluid saturation. Figure 3 a) shows the variation of the computed $\mathrm{Al}$ as a function of gas saturation $\left(\mathrm{S}_{\mathrm{w}}=1-\mathrm{S}_{\mathrm{g}}\right)$ for different gas pressures. It is possible to realize that the fizz water effect is stronger at shallow reservoir conditions and for deeper reservoir conditions the variation is more gradual.

As examples, it is first discussed the case for a shallow reservoir with pore pressure of about $15 \mathrm{MPa}$ and temperature $35^{\circ} \mathrm{C}$, a few percent of free gas with specific gravity of 0.88 (corresponds to bulk modulus of $36 \mathrm{MPa}$ ) which can dominate the fluid mixture properties, and thus the physical properties of the saturated rock. It is usually the first $5 \%$ of the gas saturation that causes a significant 


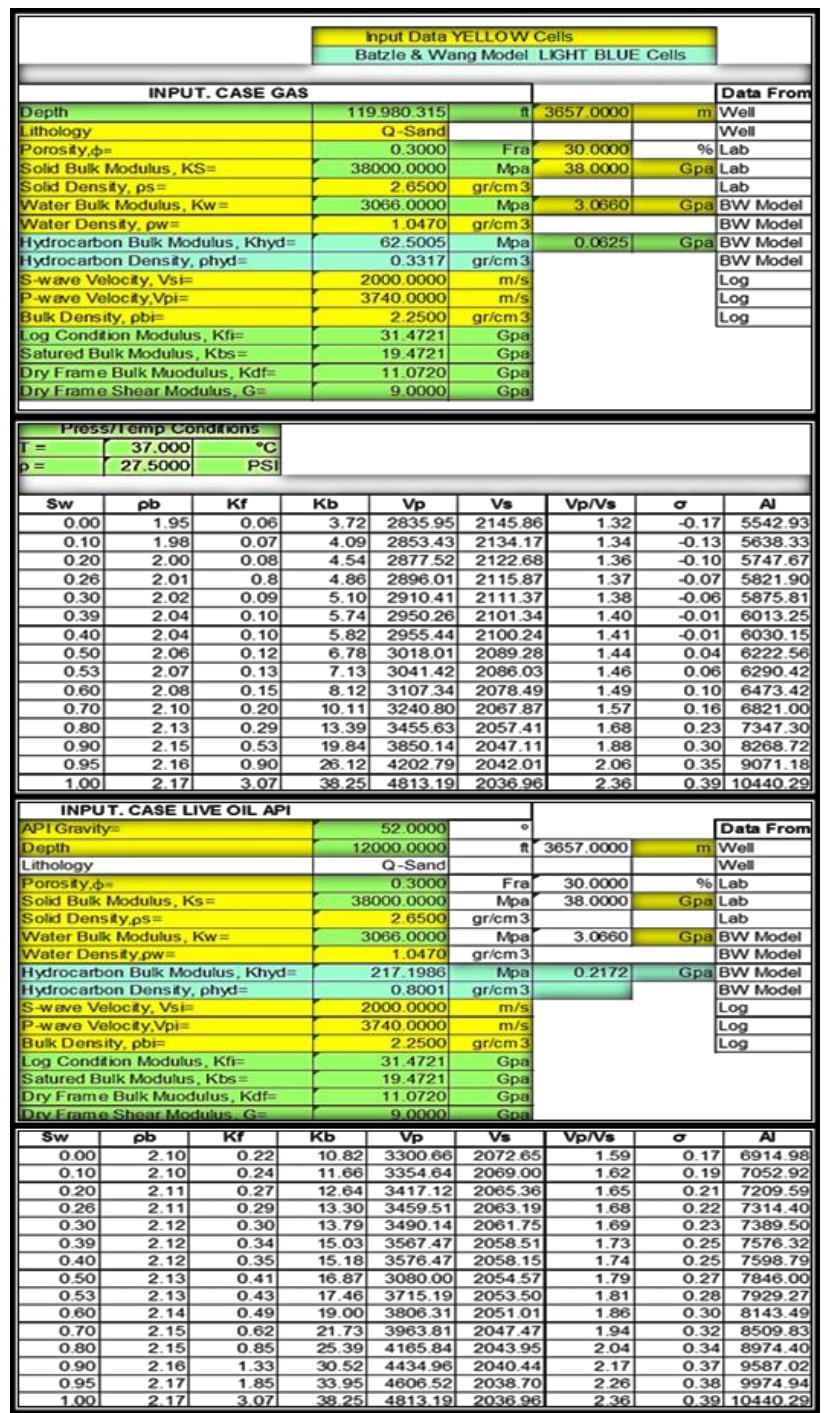

Figure 2. Gassmann model for gas and oil cases in deep part is the gas case and the lower part is for light oil at 52 API. The yellow rows depict the input data that comes from well-logs, cores, or from analogous oil/gas fields. The values for pressure, temperature, API and the green rows come from the Batzle and Wang (BW) model.

change in velocity in reservoirs. This concept referred to as fizz water effect has been widely accepted as a cause of many false AVO anomalies leading to dry holes.

For the case of a deeper reservoir in where pore pressure is $55 \mathrm{MPa}$, and temperature is $75^{\circ} \mathrm{C}$, gas with specific gravity 0.88 has a bulk modulus of $125 \mathrm{MPa}$ (Figure $3 \mathrm{~b}$ ), below). In such a case the Al shows a more gradual variation with gas saturation compared with shallow reservoir conditions. Thus, the fizz water effect decreases as the pressure increases. This reduces the risk of a false AVO anomaly in deep exploration projects as compared with projects at shallower depths. As the pressure drops, the fluid modulus and density also drop significantly, so that free gas can enter the reservoir.

\section{Effect of API and GOR in seismic response}

\section{1) API (American Petroleum Institute) Grade Analysis}

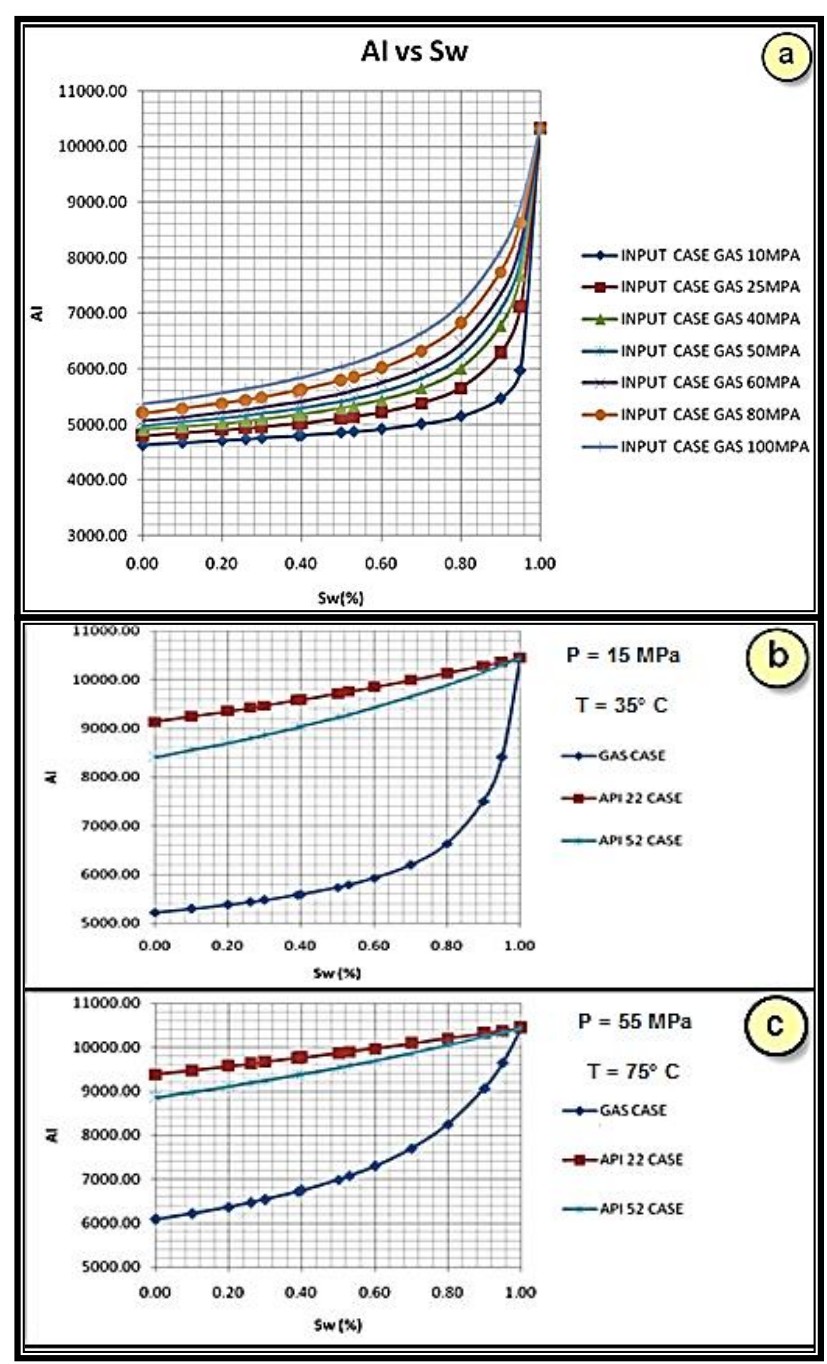

Figure 3. a) Calculated acoustic impedance (Al) response plotted against gas saturation for different gas pressures $\left(S_{w}=1-S_{g}\right)$. The dark blue curve shows a high gas bulk modulus corresponding to shallower reservoir conditions, whereas the light blue curve shows a more gradual change as for the deeper reservoirs. b) Calculated acoustic impedance response plotted as a function of gas saturation for shallow reservoir conditions: pore pressure $15 \mathrm{MPa}$ and temperature $35^{\circ} \mathrm{C}$, where the $A l$ is seen to be sensitive to first $5 \%$ of the gas saturation. c) Al plotted as function of gas saturation for deeper reservoir conditions: pore pressure: $55 \mathrm{MPa}$ and temperature: $75^{\circ} \mathrm{C}$. In such a case, the Al shows a more gradual change as a function of gas saturation. In both graphics it is shown the response for API 22 and API 55.

A primary goal of Amplitude Versus Offset (AVO) analyses is to identify in-situ pore fluids. Such anomalies are caused by a drop in effective fluid modulus. This means lowering the compressional wave velocity but leaving the shear wave velocity relatively unchanged. In some cases, there is little distinction between liquid-phase and gas-phase in the reservoir. Also, during production, the reservoir pressure changes. Such changes can alter the P-velocity, which in turn can substantially alter the 
seismic response. Thus, it is useful to study the variation of elastic properties together with the hydrocarbon API density.

\section{2) GOR Analysis}

Similarly, the gas-oil-ratio (GOR) affects the fluid properties by decreasing the density, bulk modulus and velocity with increasing GOR. These changes in elastic properties have a strong impact on the seismic signature. For example, it can occur in a gas case at different pressure and temperature conditions or light oil at low pressure conditions which in turn creates a larger amplitude seismic response (Bright Spot). The smaller Poisson's ratio at reservoir conditions produces a large contrast between the reservoir formation and the overlying shale layer, in turn creating a Class III amplitude variation with offset (AVO) effect (for more details see next paragraph, AVO Model). In Figure 4 it is possible to appreciate the calculated $\mathrm{Al}$ as a function of gas saturation $\left(S_{w}=1-S_{g}\right)$ at low (Figure 4 a)) and high (Figure 4 b)) pressure and temperature conditions, as well as different GOR values.

\section{AVO Model}

Amplitude variation with offset (AVO), computes the seismic response due to the contrast in elastic properties between two adjacent layers (Bulloch, 1999). The change in amplitude of the reflection coefficient with offset is a function of the contrast in elastic properties across the interface (Rutherford et al., 1989). Class I AVO response has a large positive reflection at zero offset and becomes smaller with increasing offset. Class II AVO response has a small positive reflection at zero offset and becomes very small or even negative with increasing offset. Class III AVO response has a negative reflection at zero offset and increasingly large negative reflections at increasing offsets. Later a Class IV AVO anomaly was defined (Castagna, 1997). Class IV AVO anomaly is large negative amplitude.

The abovementioned subdivision corresponds to the classical AVO behavior. For example, a sand-shale interface often displays a negative reflection response that is increasingly large with offset in a CMP gather. The angle of incidence for the reflections is also changing from trace to trace in the prestack gather. AVO attributes, like gradient and intercept, are computed in special crossplots. The Zoeppritz (1919) equations are a set of equations that describe the partitioning of seismic wave energy at an interface, typically a boundary between two different layers of rock. The reflection and transmission coefficients depend on the angle of incidence and the material properties of the two layers on both side of the interface, (Bulloch, 1999).

Approximations derived from Zoeppritz equations are frequently used for calculation. The most usual simplifications are: Aki and Richards (2002), Shuey (1985) and Hilterman (1989). Besides, these approximations are derived under different hypothesis, while the most common condition is being that angles of incidence less than $30^{\circ}$ and $\mathrm{Vp} / \mathrm{Vs}=2$, (Bulloch, 1999).

The Shuey (1985) simplification was made in terms of variations of the Poisson ratio $(\Delta \sigma)$, which is useful to

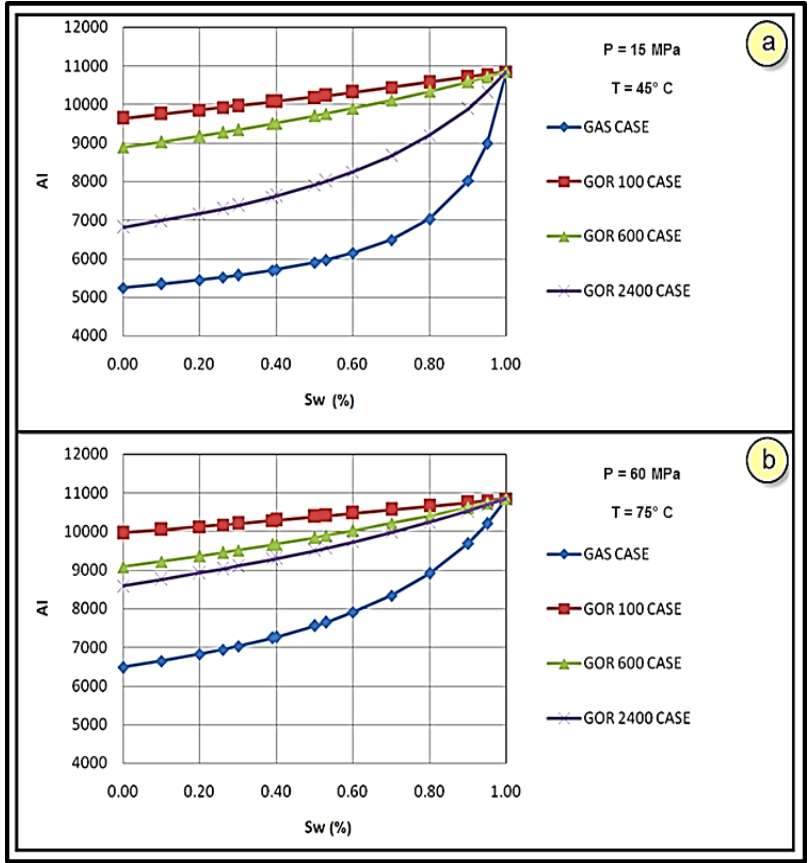

Figure 4. The calculated $A l$ as a function of gas saturation $\left(S_{w}=1-S_{g}\right)$ at low (Figure 4 a)) and high (Figure 4 b)) pressure and temperature conditions, as well as different GOR values. Notice that the dynamic range of the $A$ l values for all GOR values (100, 600 and 2400) shown are higher for low temperatures and pressures.

illustrate the fluid dependence. A few more assumptions are needed about the background rock properties, which are: (i) density changes are proportional to $\mathrm{Vp}$ changes or Gardner hypothesis, and (ii) the background Poisson ratio is 0.33 , which is equivalent to $\mathrm{Vp} / \mathrm{Vs}=2$. Hilterman (1989) give a very simple equation to model the reflectivity against the angle of incidence and the variation of the Poisson ratio:

$$
R(\theta) \approx R(0) \cos ^{2} \theta+2.25 \Delta \sigma \sin ^{2} \theta
$$

When the Hilterman approximation is applied to the gas at shallow reservoir (low pressure and temperature) conditions and to a gas at deep burial condition (high pressure and temperature), there are characteristic differences in the AVO curves. In both cases, the AVO curves for Gas, Light Oil (52 API) and Oil (22 API) reservoirs are separated. An interesting observation is that the Light Oil amplitude curve for shallow burial shows a clear AVO effect, and this AVO response is similar to the AVO curve of gas at high pressure and temperature conditions. It is apparent that the AVO response becomes more pronounced as free gas dissolves from the live oil when the pressure drops from $60 \mathrm{MPa}$ to $15 \mathrm{MPa}$, assuming dry frame effects with pressure are constant.

\section{Applications}

\section{Case Study}

This case study is located in the Southeast Basins of Gulf of México (Figure 8). The sedimentary records in this depression begun with the deposit of continental red beds during the Late Triassic and Early Jurassic, after which, 
during the Callovian, sea- waters from the Pacific invaded an extended area; low circulation and high evaporation of these waters allowed the deposition of large volumes of salt in the central part of the basin. From Late Jurassic to Late Cretaceous, carbonate deposition prevailed, changing to clastic at the beginning of the Paleogene. In the Middle Miocene, during the Serravalian, compressive stresses resulting from the lateral movement of the Chortis Block and the subduction of the Cocos Plate, against the southern end of the North American Plate, formed the folds and faults of the Chiapas- Reforma-Akal belt over a décollement at the level of the Callovian salt. Later, these structures were tilted to the NNW when the salt was mobilized northward.

The main productive reservoir has been focused, Middle Miocene shallow sandstone reservoirs, with average porosity close to $25 \%$ and permeability between

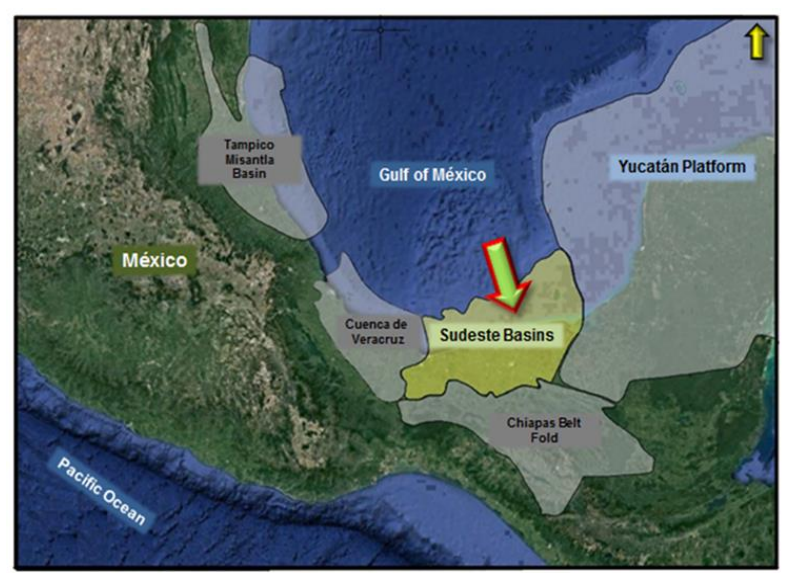

Figure 8. Location of Southeast Basins, Gulf of México. The green arrow indicates approximately the studied well position (Case Study 2) (shallow water offshore area). Courtesy of Pan American Energy Data Base.

100 to $300 \mathrm{mD}$. Generally, it is composed of between 2 and 10 sandy lithosome with 1 to $10 \mathrm{~m}$ of individual thickness, separated by limolitic sections mainly thinner. These lithosomes interdigitate laterally and composing a single unit of flow, up to 25 meters in total thickness (Padilla y Sánchez, 2007).

Figure 9 a) shows the input parameters and analysis for data from a representative well in the area. Batzle and Wang analysis were carried out for the brine and gas cases. Figure $9 \mathrm{~b}$ ) shows the variation of $\mathrm{Al}$ as a function of gas saturation $\left(S_{w}=1-S_{g}\right)$ for both the brine and gas cases. Then this analysis was extended for different pressures as well as different GOR scenarios, and the results are shown in Figure 10. Notice the Al variation reduces as the GOR values decrease. The curves behavior shown in this Figure, allow pointing out that the

Al variation reduces as the GOR values decrease. The results reinforce the conclusions described from seismic data. The Figure 11 compares a Prestack Time Migrated angle gather with a Modeled angle gather, and it is possible to appreciate similar variations in the amplitudes. Notice the Amplitude variations as a function of Angle for the events representing the tops of reservoirs $A$ and $B$ (marked on the gathers) below the gathers. The

\begin{tabular}{|c|c|c|}
\hline \multicolumn{2}{|l|}{ INPUT. CASE: GAS MODEL } & \\
\hline Depth & 7316.2730 & \\
\hline Lithology & Q-Sand & \\
\hline Porosity, $\phi=$ & 0.2800 & Fra \\
\hline Solid Bulk Modulus, Ks= & 38000.0000 & Мра \\
\hline Solid Density, $\rho s=$ & 2.6500 & $\mathrm{gr} / \mathrm{cm} 3$ \\
\hline Water Bulk Modulus, $\mathrm{Kw}=$ & 3066.0000 & $\mathrm{Mpa}$ \\
\hline Water Density,pw= & 1.0200 & $\mathrm{gr} / \mathrm{cm} 3$ \\
\hline Hydrocarbon Bulk Modulus, Khyd= & 436.4714 & Мpa \\
\hline Hydrocarbon Density, phyd= & 0.1775 & $\mathrm{gr} / \mathrm{cm} 3$ \\
\hline S-wave Velocity, Vsi= & 2511.0000 & $\mathrm{~m} / \mathrm{s}$ \\
\hline P-wave Velocity,Vpi= & 4181.0000 & $\mathrm{~m} / \mathrm{s}$ \\
\hline Bulk Density, pbi= & 2.3800 & $\mathrm{gr} / \mathrm{cm} 3$ \\
\hline Log Condition Modulus, Kfi= & 41.6042 & Gpa \\
\hline Satured Bulk Modulus, Kbs= & 21.5960 & Gpa \\
\hline Dry Frame Bulk Muodulus, Kdf= & 10.9796 & Gpa \\
\hline Dry Frame Shear Modulus, G= & 15.0062 & Gpa \\
\hline
\end{tabular}

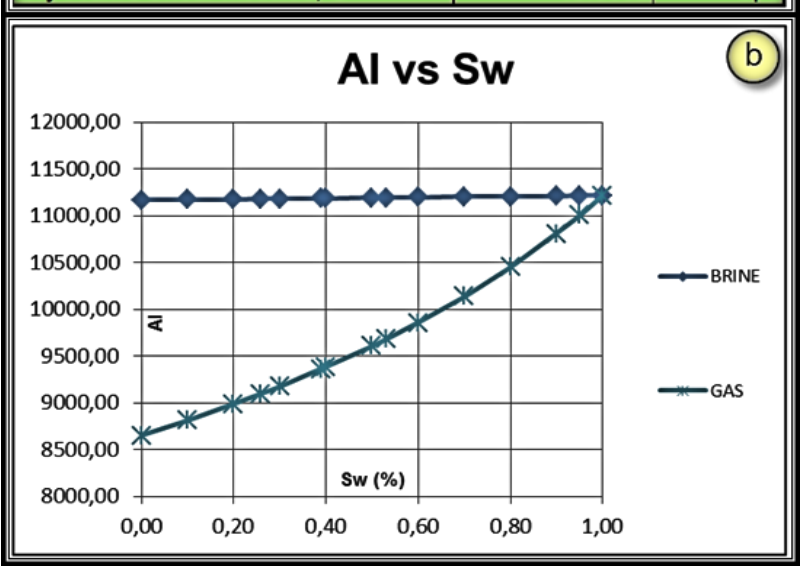

Figure 9. a) Input parameters from a representative well in the area are shown in yellow in the table. The Batzle and Wang analysis carried out for the brine and gas cases is shown in green in the same table. b) Variation of calculated $A$ l as a function of gas saturation $\left(S_{w}=1-S_{g}\right)$ for both the brine and gas cases.

smooth red and blue curves are for the amplitudes, corresponding to the reservoir tops modeled gather, and the other set of curves from the seismic events. The two show similar variations. On track 3 it is possible to appreciate the angle information overlaid on the offset gather, where angles of incidence beyond 45 degrees are seen clearly. In this particular case, the Batzle and Wang model was extended to different pressures as well as different GOR scenarios. An AVO anomaly was recognized in this area, clearly seen in the seismic data (see Figure 11).

\section{Conclusions}

Batzle and Wang model predicts the elastic fluid properties at different reservoir conditions, especially in terms of temperature and pressure. Fluid properties are very important regarding the interpretation of Direct Hydrocarbon Indicators (DHI) seen on seismic datasets.

Specific hydrocarbon types will result in typical variations in amplitude versus angle indicators. Changes in fluid phase can substantially alter the reservoir seismic response. However, these effects are predictable in many cases and should be explicitly incorporated in standard 


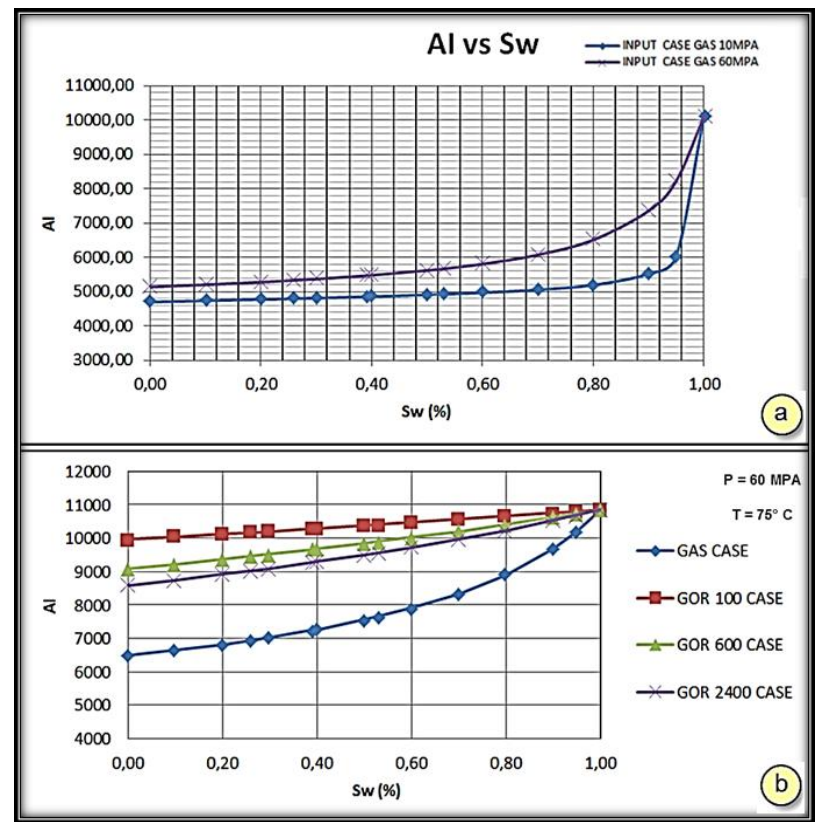

Figure 10. a) Calculated $A l$ as a function of gas saturation $\left(S_{w}=1-S_{g}\right)$. The blue curve represents a high gas bulk modulus representative of well conditions, and the violet curve shows the low gas bulk modulus (typical of shallow reservoir conditions). b) Calculated $A$ l as a function of gas saturation $\left(S_{w}=1-S_{g}\right)$ for different GOR values. Notice the $A$ l variation reduces as the GOR values decrease.

G\&G reservoir characterization workflow. Therefore, it is suggested that such analysis be carried out routinely to increase the confidence in interpretation and value addition in exploration and exploitation cases.

\section{Acknowledgements}

We thank Wintershall Energía S. A. and Pan American Energy LLC for permission to publish the examples.

\section{References}

Aki, K., and Richards, P., 2002, Quantitative Lamont-Doherty Earth Observatory of Columbia University.

Batzle, M. and Wang, Z., 1992, Seismic properties of pore fluids, Geophysics, 57, No. 11, pp. 1396-1408.

Biot, M., 1956, Theory of propagation of elastic waves in a fluid-saturated porous solid, Journal of Acoustical Society of America, 28, pp. 168-191.

Bulloch, T., 1999, The Investigation of Fluid Properties and seismic Attributes for Reservoir Characterization, Thesis, Michigan Technological University.

Castagna, J. and Swan, H., 1997, Principles of AVO cross-plotting, The Leading Edge, SEG, 16, pp. 337342.

Chopra, S. and Castagna, J., 2014, AVO, Investigations in Geophysics No. 16, SEG.

Gassmann, F., 1951, Elastic waves through a packing of spheres, Geophysics, 16, pp. 673-685.

Hilterman, F., 1989, Is AVO the seismic

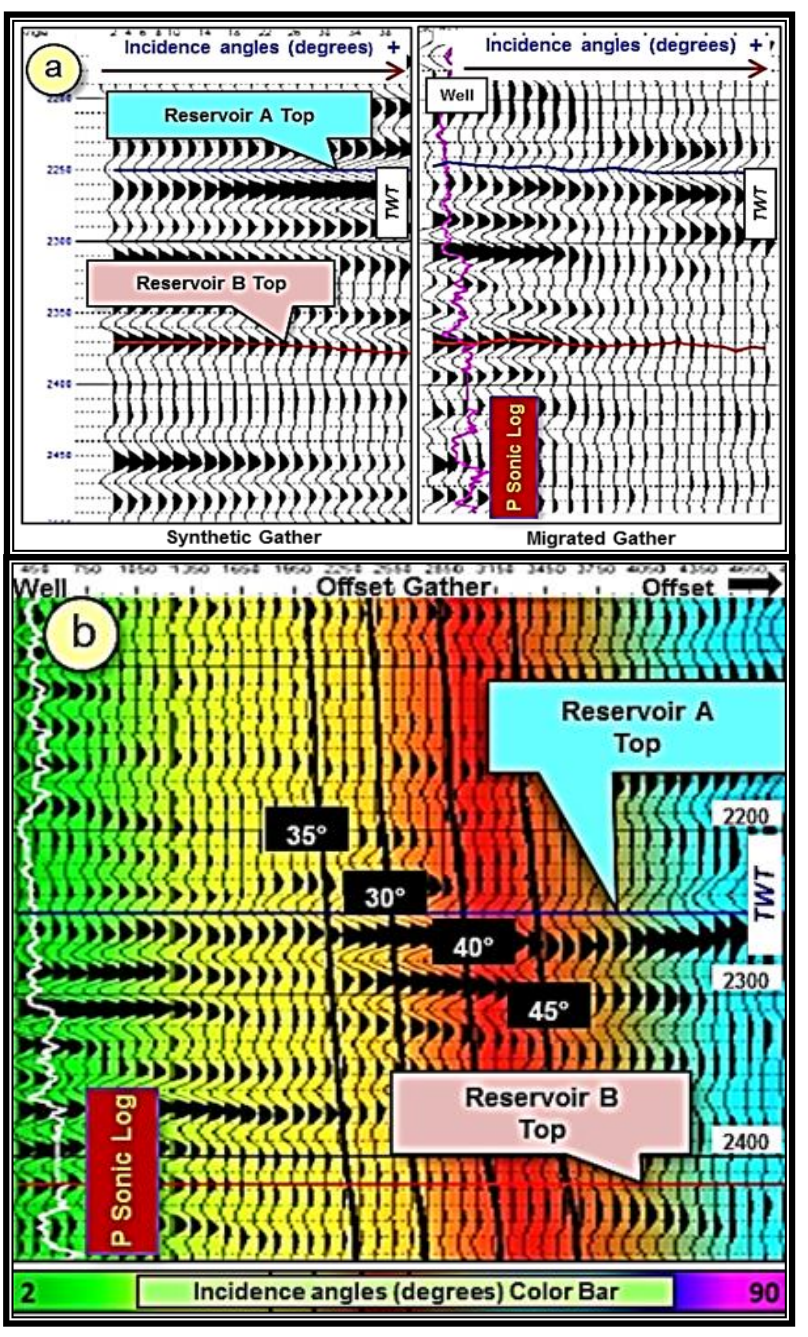

Figure 11. a) A prestack time migrated angle gather is compared with a modeled angle gather. Similar variations in the amplitudes as a function of angle for the events representing the tops of reservoirs $A$ and $B$ are shown below the gathers. b) Angle of incidence information overlaid on the offset gather, where angles of incidence beyond 45 degrees are seen clearly.

signature of rock properties? $59^{\text {th }}$ Annual International Mtg.,SEG, Expanded Abstracts, p. 559.

Padilla y Sánchez, R., 2007, Evolución geológica del sureste mexicano desde el Mesozoico al presente en el contexto regional del Golfo de México, Boletín de la Sociedad Geológica Mexicana, Tomo LIX, Núm. 1, pp. 19-42.

Rutherford, S. and Williams, R., 1989, Amplitude-versus-offset variations in gas sands: Geophysics, 54, pp. 608-688.

Shuey, R. T., 1985, A simplification of the Zoeppritz equations, Geophysics, 50, pp. 609-614.

Young, H. and Freedman, R., 2012, University Physics with Modern Physics, Addison-Wesley, ISBN 978-0-321-69686-1, p. 356.

Zoeppritz, K., 1919, Erdbebenwellen VIIIB, On the reflection and propagation of seismic waves, Göttinger Nachrichten, I, pp. 66-84. 